\title{
Exploding explicatures
}

Article

Accepted Version

Borg, E. (2015) Exploding explicatures. Mind and Language, 31 (3). pp. 335-355. ISSN 1468-0017 doi:

https://doi.org/10.1111/mila.12109 Available at https://centaur.reading.ac.uk/40443/

It is advisable to refer to the publisher's version if you intend to cite from the work. See Guidance on citing.

To link to this article DOI: http://dx.doi.org/10.1111/mila.12109

Publisher: Wiley-Blackwell

All outputs in CentAUR are protected by Intellectual Property Rights law, including copyright law. Copyright and IPR is retained by the creators or other copyright holders. Terms and conditions for use of this material are defined in the End User Agreement.

\section{www.reading.ac.uk/centaur}

\section{CentAUR}

Central Archive at the University of Reading

Reading's research outputs online 


\title{
Exploding Explicatures
}

\begin{abstract}
:
'Pragmaticist' positions posit a three-way division within utterance content between: (i) the standing meaning of the sentence, (ii) a somewhat pragmatically enhanced meaning which captures what the speaker explicitly conveys (following Sperber and Wilson 1986, I label this the 'explicature'), and (iii) further indirectly conveyed propositions which the speaker merely implies. Here I re-examine the notion of an explicature, asking how it is defined and what work explicatures are supposed to do. I argue that explicatures get defined in three different ways and that these distinct definitions can and do pull apart. Thus the notion of an explicature turns out to be ill-defined.
\end{abstract}

Word Count: (inc. bibliography and footnotes): 10,000

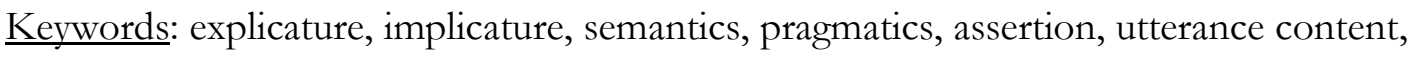
contextualism, Relevance Theory. 


\section{Exploding Explicatures*}

In recent years advocates of what I'll here term 'Pragmaticist' positions (the term is from Carston 2009, see also Neale's 2007 'linguistic pragmatism') have argued for a three-way division within what Grice termed 'the total signification of an utterance'. They suggest that when someone makes a communicative utterance we should hold apart: (i) the standing meaning of the sentence uttered, (ii) a somewhat pragmatically enhanced or enriched meaning which captures what the speaker says/asserts (following Sperber and Wilson 1986, I will label this the 'explicature'), and (iii) further indirectly conveyed propositions which the speaker merely implies (implicatures). In this paper, I want to re-examine the Pragmaticist's notion of an explicature, asking how it is defined and what work explicatures are supposed to do. I will suggest that we can find three different ways in which the notion of an explicature gets defined in the literature: on the one hand, there is the formal, canonical definition, offered in terms of the relationship between explicatures and standing meanings, or in terms of the kinds of formal tests that explicature contents are held to pass. Alternatively, there are psychological definitions of explicature content, in terms of the content entertained by speakers or hearers during on-line processing of communicative acts. Finally, there are communicative definitions of explicatures in terms of the content speakers are publically held to have asserted. My contention is that these distinct definitions of explicatures can and do come apart. There is, I will argue, no single, univocal

\footnotetext{
${ }^{*}$ For helpful comments and discussion, thanks are due to members of the AHRC Research Network on Pervasive Context (especially Jumbly Grindrod, Nat Hansen, and Mark Pinder), and audiences at Cambridge, Göttingen, KCL, Oxford, and Southampton. I'm also very grateful to Robert Stainton and an anonymous reviewer for Mind and Language, whose comments significantly improved the paper.

Address for correspondence: Emma Borg, Director, Reading Centre for Cognition Research, Philosophy

Department, University of Reading, Reading RG6 6AA.

Email: e.g.n.borg@reading.ac.uk
} 
content which answers to all these divergent needs, so the notion of an explicature turns out to be ill-defined. Thus I'll conclude that Pragmaticist approaches which rest on this notion are seriously compromised. ${ }^{1}$

The structure of the paper is as follows: in $\$ 1$ I'll set out the kind of Pragmaticist model I'm interested in and explore the various ways in which explicatures get defined. As we will see, there is a canonical definition (in terms of expansions of logical form) and a range of further, more functional definitions (given in terms of the work explicatures do). $\$ 2$ will investigate the canonical definition of explicatures and reject it as insufficient. $\$ \$ 3-4$ will then investigate the functional definitions: $\$ 3$ will look at psychological definitions of explicatures, and $\$ 4$ will examine third-person, communication-based definitions. However I will argue that while there are contents which fulfil each of these functional roles, there is no reason to suppose that these contents necessarily line up either with each other or with canonically defined explicature content. Explicatures, then, as the things which are supposed to simultaneously satisfy all three roles, simply explode.

\section{Introducing Explicatures}

When thinking about the total signification of a linguistic communicative act we might, following Grice's seminal work, hold that it divides into two distinct elements:

a) what is said by the sentence

\footnotetext{
${ }^{1}$ The main targets of this paper are Relevance Theorists, such as Dan Sperber and Deirdre Wilson, and Robyn Carston, together with Kent Bach and Francois Recanati (when arguing for Contextualism or Truth-conditional Pragmatics). All these theorists apparently endorse the idea that intuitions about what a speaker says or asserts can be grounded in or explained by an independently individuated notion of explicature content (i.e. a slightly pragmatically enhanced content). It is this assumption which will be challenged in what follows. However, as a referee for this journal pointed out, there might be other ways to be a Pragmaticist, ways which don't fall foul of this assumption, and it is right that this is a possibility left open in what follows.
} 
b) what is (merely) implied

For Grice, 'what is said by a sentence' is given by compositional meaning (word meaning plus structure) together with certain limited contextual processes (namely, disambiguation and reference determination for things like indexicals and demonstratives). Yet, as Grice made clear, in a successful communicative exchange speakers may well get across content beyond 'what is said by the sentence'. Thus Grice also recognised an additional kind of content - 'what is implicated' - that can be inferred from what the sentence says together with the general principles of good communication. ${ }^{2}$ In recent years, however, many theorists have suggested that Grice's division cross-cuts important distinctions and they have instead proposed an alternative, three-way divide, between:

a) The standing meaning of the sentence, given by lexical content and syntactic structure alone (for reasons sketched below, we might think of these as incomplete logical forms')

b) The propositional content recovered on the basis of (i) via a range of pragmatic processes (e.g. disambiguation, reference determination, and what we will below term 'free pragmatic effects') which yields what the speaker explicitly asserts

c) What the speaker indirectly conveys (the implicatures of the utterance), given by fullblown pragmatic processing.

So, to take a toy example, imagine that Jack and Jill are UK primary school children discussing their forthcoming school play:

\footnotetext{
${ }^{2}$ This is not quite accurate. In fact, Grice only requires what he terms 'conversational implicatures' be capable of being inferred: 'The presence of a conversational implicature must be capable of being worked out; for even if it can in fact be intuitively grasped, unless the intuition is replaceable by an argument, the implicature (if present at all) will not count as a conversational implicature; it will be a conventional implicature', Grice 1989: 31. However it is conversational implicatures which will be our main concern in what follows.
} 
1. Jack: 'Who should play the giant?'

2. Jill: 'I'm tall'

With respect to Jill's utterance we can individuate:

a) The standing meaning of the sentence, given by the meaning (character) of ' $\mathrm{T}$ ' and 'tall' combined in subject-predicate form.

b) What Jill explicitly says by her utterance, e.g. that Jill is tall for a UK primary school child

c) What Jill implicates by her utterance, e.g. that Jill should play the giant.

The motivation for this three-way division comes from the thought that the standing meaning of the sentence, given by composition of the lexical items in the given syntactic structure, underdetermines what a speaker directly asserts by her use of it. This underdetermination can be seen in two ways: first, some compositionally determined contents (indeed, perhaps most or even all such contents) seem to fall short of propositional content, requiring pragmatic expansion to give rise to a complete, truth-evaluable content. Thus the speaker who says 'Naoki is ready' or 'Paracetemol is better' asserts not some non-truth-evaluable fragment of content (fixed by words and structure alone) but rather a pragmatically completed proposition such as Naoki is ready to take the exam or Paracetemol is better than aspirin for curing headaches. Thus, the argument is, if we want to deal in propositional contents, we will need to allow for a richer set of pragmatic operations contributing to what is said than Grice originally envisaged. Second, the speaker who says 'There is nothing to eat' may well assert not that there is nothing to eat in some universal domain (assuming this is the content yielded within a Gricean model as 'what the sentence says') but rather that there is nothing to eat in the kitchen or nothing that the speaker wants to eat in the house right now. So, Grice's notion of what is said by the sentence fails to deliver the conversationally appropriate content we intuitively take the speaker to have asserted. From a theoretical perspective, then, the suggestion is that if we want to isolate a content which matches our intuitions about asserted content, we need to allow a richer set of pragmatic processes to operate over standing meaning than we might initially have envisaged. What we need is not 
Grice's notion of 'what is said by the sentence', with its oddly limited set of allowable pragmatic processes, but rather the result of some richer set of pragmatic operations. Following Sperber and Wilson 1986, I will label this content the 'explicature'.

The set of pragmatic processes which give rise to explicatures are richer than those which give rise to Grice's 'what is said by the sentence', for alongside disambiguation and reference assignment for indexicals, demonstratives, and tense markers, explicatures are also the result of what we might term 'free pragmatic effects' (see Recanati 2004). Free pragmatic effects are contextual effects on what the speaker says which are not triggered by anything in the syntactic or lexical form of the sentence. They are not bottom-up, mandatory contextual processes (like the saturation of an indexical with its referent) but rather are triggered solely by the conversational setting in which the sentence is produced. They are thus top-down, entirely optional processes. So, for instance, the provision of a referent for the indexical in an utterance of 'I've eaten' is a bottom-up, mandatory pragmatic process - the presence of the word 'I' tells us, first, that we must look to a context of utterance to secure a value for this expression and, second, it mandates which aspect of the context must be appealed to (namely, the producer of the token). On the other hand, the recognition that the person who utters 'I've eaten' in a certain context means that they've eaten recently marks a free pragmatic effect - an optional pragmatic alteration of the linguistically given content based on features of the conversational context in play. Or again, if I were to utter 'This steak in raw' in a restaurant, having just been presented with a particularly bloody piece of meat, I would be understood as asserting not the literal meaning this steak is uncooked but rather a pragmatically modulated meaning along the lines of this steak is undercooked. Arriving at this meaning is a top-down process (driven solely by high-level, conversational considerations) and it is fully optional (in other contexts, an utterance of 'this steak is raw' could express just the literal, unenhanced meaning). We'll look further at the notion

\footnotetext{
${ }^{3}$ Bach introduces the term 'impliciture' for the same kind of content; for discussion of the relationship between the two notions, see Bach 2010.
} 
of free pragmatic effects in $\$ 2$, but the claim is that what a speaker directly asserts on at least some occasions is not the impoverished literal meaning of the sentence she produces but some suitably pragmatically modulated content - a content close to the compositional meaning of the sentence uttered but refined or enriched in certain ways so as to provide a complete, conversationally appropriate proposition. ${ }^{4}$

So, consider the following case (from Carston 2009b: 35):

A: 'How was the party?'

B: 'There was not enough drink and everyone left'

Via a combination of bottom-up saturation and top-down free pragmatic effects, hearers are able to construct an explicature for B's utterance along the following lines:

(B1) Explicature: there was not enough alcoholic drink to satisfy the people at [the party $]_{i}$ and so everyone who came to [the party $]_{i}$ left $[\text { the party }]_{i}$ early.

This in turn allows hearers to infer a further proposition as that which the speaker has implicated:

(B2) Implicature: the party was no good.

According to Relevance Theory, there exists a continuum of non-literal or loose use cases, ranging from relatively minor alterations of literal meaning at one end of the spectrum through to more radical departures, as with some figurative uses, at the other. So for instance, to take an example from Wilson 2011: 180, the speaker who says metaphorically 'Robert is a computer' directly asserts the proposition that Robert is a computer*, where 'computer*' is an ad hoc concept formed by broadening the literal meaning of 'computer' to allow it to include people in its extension. This explicature can then give rise to a range of further implicatures such as that Robert lacks feelings, Robert processes information well, etc.

\footnotetext{
${ }^{4}$ Bach 1994: 124 'Impliciture...is a matter of saying something but communicating something else instead, something closely related to what is said'.
} 
Clearly, then, explicatures have an important role to play in the Pragmaticist framework, but beyond the examples above, how exactly should we think of them? In the literature, the primary definition (e.g. Sperber and Wilson 1986: 182, Carston 2009b: 41) of an explicature is as follows:

\section{Canonical Definition:}

An explicature is a pragmatically inferred development of logical form, where implicatures are held to be purely pragmatically inferred (i.e. unconstrained by logical form). ${ }^{5}$

However, explicatures are also functionally characterised in a number of different (and potentially divergent) ways, as follows:

i. Explicatures are what the speaker intends directly to communicate; Sperber \& Wilson 1986: 183, Carston 2009b: 36.

ii. Explicatures are the first content hearers recover via relevance processing; Sperber \& Wilson 1986:184-5.

iii. Explicatures provide the essential premise for inferring further (implicated) propositions; Carston 2009b: 41.

iv. The explicature is the proposition on which S's utterance is judged strictly true or false; Carston 2009b: 36.

v. An explicature is an explicitly communicated proposition (Sperber and Wilson 1986: 182).

\footnotetext{
${ }^{5}$ Sperber and Wilson 1986: 182: 'An assumption communicated by an utterance $U$ is explicit (and hence is an explicature) if and only if it is a development of a logical form encoded by U'. Note that they also allow explicatures to come in degrees; the quote continues: 'explicitness is a matter of degree: the greater the contribution of encoded meaning the more explicit the explicature is and the greater the contribution of pragmatically inferred content the less explicit it is'.
} 
In the next three sections I'd like to consider each of these ways of understanding what an explicature is, asking if they yield a coherent theoretical notion. In $\$ 2$ I'll explore the canonical definition of explicatures and argue that, on its own, it fails to yield an individuation of explicatures which distinguishes them from implicatures. Thus, on its own, I'll suggest the canonical definition is inadequate. In $\iint 3-4$ I'll consider reinforcing the canonical definition with the functional definitions of explicatures from (i-v) but suggest that this move is also problematic. For though each of the additional definitions may succeed in isolating a kind of content, there is no guarantee that there is a single kind of content which plays all the functional roles nor that the content playing any one of these roles necessarily lines up with that individuated by the canonical definition of an explicature. Explicatures, defined simultaneously as certain kinds of expansions of logical form, what is psychologically present, and as what is explicitly communicated, simply do not exist.

\section{Explicatures as Developments of Logical Form?}

Explicatures are held to be pragmatic developments of logical form, but not all pragmatic developments of logical form are held to be explicatures. So we need an answer to the question of when a pragmatic development of logical form constitutes an explicature and when it doesn't. This question arises in two ways I think: first, is there a limit on the kinds of free pragmatic effects which contribute to explicatures? Second, for any kind or kinds of free pragmatic effects which can contribute to explicatures, which instances of these kinds are explicature-generating (i.e. does every instance of a given kind result in an explicature or only some? And if only some, which ones?). I'll consider these questions in turn.

\subsection{How Many Kinds of Free Pragmatic Effects are Explicature Generating?}

Traditionally, theorists have recognised two distinct kinds of free pragmatic effects: 

a. unarticulated constituents
b. modulation

Unarticulated constituents (UCs) are supposed to be additional bits of content which are provided to the proposition expressed from the context of utterance, even though nothing in the syntactic form of the sentence demands these additions. ${ }^{6}$ The classic example of a UC is the provision of a location for the use of a weather predicate. So, for instance, if Jones looks out of her window in Oxford and says 'It's raining' the suggestion is that she may directly express the proposition that it is raining where Jones is, or that it is raining in Oxford, even though no element in the sentence expressly triggers the incorporation of a location (Recanati 2002). Or again, theorists have suggested that pragmatically enhanced readings of logical vocabulary might be traced to the operation of UCs, so that the temporally-ordered reading of 'Jill got married and had children' as Jill got married and then had children might be explained by the presence of a UC. Finally, one of our earlier examples of a free pragmatic effect - interpreting an utterance of 'I've eaten' as I've eaten recently - would seem to be a case of adding new, pragmatically provided material to the proposition expressed, i.e. to be an instance of a UC. Modulation, on the other hand, is a pragmatic process whereby the meanings of elements already present in the logical form of the sentence are modified. For instance, our earlier example of 'This steak is raw' being understood as meaning that this steak is undercooked was an instance of modulation - the literal meaning of 'raw' was replaced, due to conversational demands, with an ad hoc, loosened meaning raw* which includes slightly cooked items in its extension. Or again, when someone utters the sentence 'I need a red pen' while marking they may be held to express the modulated

\footnotetext{
${ }^{6} \mathrm{It}$ is, perhaps, fair to say that in the early days of debates about free pragmatic effects it was the notion of unarticulated constituents that was centre stage (e.g. see Perry's seminal 1986 article), although modulation is clearly present in, for instance, Sperber and Wilson 1986. It also seems to be the notion of a UC which fits most comfortably with the notion of 'a development of logical form' (see \$3).
} 
concept $r e d^{*}$, a more restricted or narrow concept (than the literal meaning of 'red') which perhaps contains only objects which write in red ink in its extension.

Together, then, these two free pragmatic effects of unarticulated constituents and modulation address the worry that linguistic semantics underdetermines asserted speaker meaning, since via their operation we can contextually complete and refine bare standing meanings to yield what the speaker explicitly conveys. However one question we need to ask is whether we really need two distinct kinds of pragmatic process here, i.e. do we really need both unarticulated constituents and modulation? For it seems at least in principle possible that every effect handled by a UC could instead be handled by modulation.

For instance, take the classic case of locational elements for weather predicates, traditionally handled as UCs. One alternative option would be to treat the meaning of weather terms as already specifying a location (so that, say, 'rain' means rain-at-l for some contextually determined value of I. In this case any reading of 'It's raining' which lacked a determinate location (e.g. Recanati's 2002: 317 weathermen example) could be understood as a case of pragmatic loosening: 'rain' comes to express the modulated concept rain* meaning simply rain or rain somewhere or other. A second option would be to treat the meaning of 'rain' as lacking a contextually specified location (so that 'rain' means $\exists x<$ rain, $x>$ or rain punkt) and then explain location-specific readings as arising from pragmatic narrowing, whereby 'rain' comes to express an ad hoc concept rain* meaning rain-at-l for some contextually specified value of $l$. At least prima facie then it seems that the work traditionally reserved for UCs could in principle be carried out by the more general mechanism of modulation. ${ }^{7}$ This might be thought to be a good thing since (again, at least prima facie) a process which can only operate over extant elements in the LF would seem to be at least somewhat more constrained than a process which can introduce entirely novel elements into the LF. Thus a modulation-only story might appeal to a

\footnotetext{
${ }^{7}$ Deirdre Wilson has suggested (pc) that perhaps the only real role for UCs might be to accommodate metalinguistic moves.
} 
Pragmaticist who is concerned to show that her appeal to pragmatics is not excessively liberal. ${ }^{8}$ Whether or not all appeals to UCs can ultimately be replaced by appeals to modulation remains, however, a somewhat open question since it is currently not clear exactly what the constraints are on broadening and narrowing of senses. Perhaps there is a reason to think that 'rain' cannot be broadened or narrowed in the ways envisaged above, or to think that the move from the simple conjunctive reading of 'and' to a temporally or causally ordered interpretation cannot be the result of some kind of conceptual narrowing, but certainly as things stand it is not clear why the Pragmaticist should resist these kinds of moves. Yet whether they opt for UCs and modulation, or modulation only, Pragmaticists face a second, more fundamental question, namely: given either kind of free pragmatic effect, which instances of it contribute to explicatures and which to implicatures?

\subsection{Which Instances of Free Pragmatic Effects Contribute to Explicatures and Which to Implicatures?}

Given that Pragmaticists want to preserve the distinction between directly expressed content (the explicature) and indirectly conveyed content (implicatures), it is clear that not all free pragmatic effects should be treated as contributing to directly expressed content - at least some such effects yield only implicatures. So, the question for the Pragmaticist is how to hold apart these two: is there a way, beyond a simple appeal to intuition, to tell when a free pragmatic effect generates an explicature and when it generates an implicature? Without such a mechanism, as Stanley 2002 argues, free enrichment could turn out to be excessively liberal, for instance allowing an utterance of (3a) to directly express (3b):

3a. John likes Sally.

3b. John ${ }_{1}$ likes Sally and his ${ }_{1}$ mother.

\footnotetext{
${ }^{8}$ Or it might not appeal - Carston and Hall 2012: 62 suggest in passing that a narrowing account of weather predicates would be 'counter-intuitive'.
} 
While some Pragmaticists have objected to Stanley's particular examples on pragmatic grounds (see Hall 2008), still it seems his general point holds good: unless Pragmaticists can find a way to constrain the operation of free pragmatic effects, they risk allowing that (given the right circumstances) any content at all can be directly expressed. Yet this would seem to erode the desired distinction between explicatures and implicatures.

In response to this concern Pragmaticists have proposed a number of tests for isolating explicatures from implicatures. Probably the most promising of these is the 'Scope Test' (see, for instance, Carston 1988) whereby an element introduced via free pragmatic effects counts as part of an explicature only if it falls under the scope of logical operators such as negation or a conditional. In this way, for instance, the temporally ordered sense of 'and' (introduced via UCs or modulation) must form part of the explicature of an utterance of 'Jill drank five beers and drove home' because there appears to be a truth-conditional difference between 'If Jill drank five beers and drove home then she can be arrested for drunk driving' and 'If Jill drove home and drank five beers then she can be arrested for drunk driving. ${ }^{9}$ However, although the Scope Test is attractive it does not seem that it can be decisive in holding apart explicature and implicature content. There are two reasons for this: first, as Carston and Hall 2012 point out, the scope test applies to sentences at a type level, whereas the explicature/implicature distinction operates at the token level. What counts as the explicature of some utterance $u$ may differ from context to context, but claims about the content which falls under the scope of an operator would seem to be context-invariant. Secondly, it seems that some elements of content which intuitively we may not want to count as part of what is explicitly communicated will also fall under the scope of operators. So for instance, as Camp 2012 points out, it seems that both metaphor and sarcasm can embed within conditionals (e.g. 'If she is the cream in your coffee then you should marry

\footnotetext{
${ }^{9}$ A similar kind of appeal to the judgements of truth and falsity surrounding utterances can be found in the truthevaluation tests of Recanati 2004: 15 and Noveck's work on scalars, e.g. Noveck 2004.
} 
her', 'If you come up with one more brilliant idea like that then you'll be fired'). ${ }^{10}$ Thus scope effects alone seem unable to differentiate explicatures and implicatures.

The most recent candidate for constraining the operation of free pragmatic effects comes from Hall 2008 and Carston and Hall 2012 who propose that 'the ultimate arbiter' (2012: 71) for what constitutes an explicature and what an implicature is the derivational distinction between local and global pragmatic inference - an effect which modifies a subpart of the linguistically encoded meaning counts as part of the explicature, while one which operates on fully propositional forms contributes to implicatures. This proposal would explain why Stanley's example above could only ever count as an implicature, since the move from John likes Sally to John, likes Sally and his, mother apparently involves an entirely new proposition being simply stapled on to the original content via conjunction introduction. However, on reflection, it's not clear that locality can really do the work required here either, since some local enrichments apparently capture implicature content. So consider the following exchange:

A: Do you want to have dinner?

B: $\quad$ I'm going to the cinema.

The question we need to ask is: how should B's utterance content be modulated? It seems there are several options available here. For instance, we might choose to pragmatically narrow the concept of GOING-TO-THE-CINEMA to GOING-TO-THE-CINEMA-TONIGHT. Such a narrowing would be licensed in order to make B's response relevant to A's inquiry and to allow

\footnotetext{
${ }^{10}$ As a reviewer pointed out, relevance theorists (e.g. Carston 2005, Ch.5) acknowledge metaphor embedding and indeed use it as an argument for explicature content, taking it to show that metaphorical content can constitute the explicit asserted content of an utterance. However, it seems less likely that relevance theorists will want to allow that sarcasm and irony contribute to explicit content. Thus we need an explanation of why the appearance of scope embedding for metaphors leads to their inclusion in explicature content, while the appearance of scope embedding for ironic or sarcastic content is taken not to reveal their status as part of explicature content (with only implicature content really embedding in these cases). Without an explanation for this divergence, I think there is still a worry that scope effects are not sufficient on their own to disentangle explicature and implicature content.
} 
A to then infer (as an implicature) the proposition that $B$ is unable or unwilling to bave dinner with me tonight. On the other hand, however, it seems perfectly possible that we might choose to narrow the concept of GOING-TO-THE-CINEMA to something like GOING-TO-THE-CINEMAAT-A-TIME-THAT-MAKES-HAVING-DINNER-WITH-A-IMPOSSIBLE. Both of these are, it seems, perfectly local effects, but only on the first will it be an implicature of what B says that she cannot have dinner with A (on the second it looks like something she directly asserts). Once again, then, it seems that it is not the mechanism introduced to constrain the operations of free pragmatic effects which is really doing the work here but rather a background appeal to our intuitions about what the speaker has directly committed herself to versus what she has merely indirectly conveyed. ${ }^{11}$

If this is right, then it seems that none of the formal proposals currently on the table for distinguishing free pragmatic effects which give rise to explicatures from those that give rise to implicatures actually work. In which case there are, I think, two options available for the advocate of explicatures: on the one hand they might decide to reject the call for an objective criterion or test by which to hold apart explicatures and implicatures, relying instead on a direct

\footnotetext{
${ }^{11}$ It might be objected that the second modulation really does involve an additional proposition being conjoined, expressed here via the relative clause. However I think this would be a mistake: first, although we might express the concept via the relative clause the proposed model is that it is the concept itself which is being loosened or narrowed, so while expression of the content might 'require a lot of words', to put it crudely, there is no reason to think this couldn't still be a perfectly atomic concept. Secondly, other, less complex modulations would cause exactly the same problem; e.g. I'M GOING TO THE CINEMA AT DINNER TIME TONIGHT. Third, canonical instances of modulation often require quite complex expression. For instance, consider Grice's classic case of the driver who runs out of gas and is told 'There is a gas station around the corner': here Pragmaticists have been quite happy to maintain that what is explicitly communicated is that there is an open gas station relatively close around the corner. But it is hard to see why that would count as an explicature while there is a gas station relatively close around the corner which is open would not.
} 
appeal to intuitions. Second, they might argue that we should continue the hunt for a more conclusive test.

The first option looks problematic as a way to ground a difference in kind between explicature and implicature since the intuitions to be appealed to seem to diverge widely. ${ }^{12}$ For instance, Sperber and Wilson, on the one hand, and Bach on the other, are likely to take very different stances on what constitutes the explicature/impliciture of an utterance like 'This pen is red'. For Bach holds that pragmatic input to the impliciture (his term for the content between sentence meaning and implicatures) in this case is limited to supplying a referent for 'this' (so his intuitive assessment should be that 'this is red' directly communicates a proposition like $<\alpha$, is red $>$ ). Sperber and Wilson, on the other hand, hold that both reference assignment and modulation for 'red' is required to yield the explicature (so their intuitive judgement should be that the explicature is something like $<\alpha$, is red in respect $\mathrm{f}>$ ). Furthermore, to the extent that we can get ordinary interlocutors to appreciate the distinction between explicatures and implicatures, it is not clear that we will get consistent judgements. For instance, take Sperber and Wilson's recent example:

A: We can't afford dinner at La Cantina.

B: I have money.

Sperber and Wilson suggest (draft) that B directly expresses that I bave a relatively significant amount of money (B's utterance wouldn't be true if she had only 10c to her name, for instance) and that she thereby implies that she can afford to pay for dinner at La Cantina. However, Sperber and Wilson's view on this example is at least open to question, for it seems a reasonable intuition to have that B directly expresses the claim that I have enough money to pay for dinner at La Cantina. So if all we have to go on here are intuitions, we will need much more information about exactly whose intuitions count, when and why.

${ }^{12}$ A different kind of appeal to intuition, this time concerning asserted content, will be discussed in $₫ 4$. 
I suspect then that it is the second alternative - continuing the hunt for a more conclusive way to individuate explicature content - which most Pragmaticists would prefer to pursue and, to this end, they might turn to the more functional definitions of explicature which we noted at the outset. In the next two sections, then, I'd like to turn to these additional characterisations and see if they can do the work required.

\section{Psychological Definitions of Explicatures}

As we saw in the last section, the core definition of an explicature is 'a pragmatic development of logical form'. However the last section suggested that, as it stands, this definition is problematic: first, there is a question about how many kinds of free pragmatic effects can contribute to these 'developments of logical form'. If it turns out that really there is only one device in play modulation - then we might think that the notion of 'development' in play here becomes somewhat attenuated, since we are no longer thinking of adding elements to the LF to get up to the level of a proposition (as with unarticulated constituents) but are merely modulating existing parts of LF. Secondly, and more seriously, there is the question of which instances of free pragmatic effects give rise to explicatures and which to implicatures - that is to say, how free pragmatic effects are to be constrained so as to yield just explicatures. Unless and until we have a robust criterion for assessing pragmatic effects as explicature- or implicature-relevant the notion of 'a development of logical form' is too weak to individuate the level of content which Pragmaticists want. However, as we noted in $\$ 1$, alongside the primary definition of an explicature there are also a number of collateral definitions to be found in the literature: explicatures are (i) what the speaker intends to communicate directly, (ii) the first content hearers recover via relevance processing, (iii) the essential premise for inferring further (implied) propositions, (iv) the proposition on which a speaker's utterance is judged strictly true or false, 
and (v) the proposition explicitly communicated. Perhaps, then, these additional ideas can help to make the notion of an explicature more robust?

Reflecting on the various functional definitions of explicatures, it seems that they divide into two distinct kinds: (i-iii) target psychological contents - the thoughts that the speaker or hearer has in mind during on-line processing of a communicative act. (iv-v), on the other hand, focus on the communication-theoretic role of explicatures, looking to their place in a more publically-orientated understanding of the communicative process. In the remainder of this section, I'll focus on the psychological definitions, before turning in the next section to the more third-personal accounts. As we will see, however, the problem with appealing to these further definitions is that it is not at all obvious that there is a unique content which fulfils all these functional roles nor that any content which does play a given functional role necessarily lines up with the canonical definition of explicature content in the way the Pragmaticist envisages.

\subsection{Explicatures as What the Speaker Intends Directly to Communicate}

Clearly, (at least typically) when speakers say things it is because they want to communicate things, so should we take explicature content to be that development of logical form which the speaker has it in mind to communicate directly? My worry with this proposal is that, in many cases, the speaker may not have any very definite content in mind to communicate - thoughts (at least as far as the underdetermination cases we are concerned with in this paper go) may be just as underdetermined as utterances, in which case explicatures (i.e. the slightly pragmatically enhanced contents envisaged by the canonical definition) need not be psychologically real for the speaker. For instance, when someone utters:

4) I want a red pen

it seems perfectly possible that she has not, contra Wilson 2011: 181, internally specified what kind of red pen she wants. She may simply not have thought whether she wants the pen that 
writes in red ink, or says 'red' on it, or has a red lid, etc. ${ }^{13}{ }^{14}$ This could be the case even if on being presented with one kind of red pen (say one which is red on its casing but which writes in black ink) she replies 'I didn't want that kind of red pen'. What this reflects is a perfectly general cognitive process of sharpening up our mental states after being presented with things that require us to sharpen in certain ways. Compare the case where we are in Oxford and I say 'I want to travel to London'. If you then tell me that there is a bus to London from the end of the street, I can then tell you that I don't want to take a bus. Given my other beliefs (about how slow buses are, etc.) and desires (I prefer train travel), I'm in a position to sharpen up my original claim: I want to travel to London but not by bus. Yet none of this shows that the content of my earlier thought needed to contain something about buses - indeed just consider how great the

\footnotetext{
${ }^{13}$ Wilson 2011: 181: 'when a teacher marking an essay says 'I need a red pencil', she will certainly have some specific sub-type of pencil in mind, and in order to understand her, the hearer must infer what particular type of red pencil this is.' We should note however that elsewhere Sperber and Wilson do explicitly allow for indeterminate intentions: in 1986: 55-6 they discuss the example of ostensive sniffing of sea air being used to communicate some indeterminate content about the quality of the air and in recent work they stress the possibility that communicated content may be indeterminate (Sperber and Wilson, draft).

${ }^{14}$ One suggestion here might be that if the speaker has not formed a more precise intention prior to an utterance of (4), then there is simply no more definite explicature to be recovered for her utterance. On this view, the explicature content of (4) would be allowed to vary across two contexts which differed only with respect to the speaker's intentions prior to her utterance. While defining explicature content in this way would be perfectly possible, the notion of content thus individuated could clearly come apart from the other definitions of explicature on the table.
} Defining explicature content solely as 'whatever the speaker has it in mind to directly communicate' would mean that explicatures might fail to be the first proposition that hearers recover via relevance processing (\$3.2), nor would they necessarily be the propositions which warrant recovery of implicatures $(\$ 3.3)$. Furthermore, they would fail to play the communicative role assigned to explicatures (see $\$ 4$ ). So, although a 'speaker internal' definition of explicature content is possible, such a notion would fail to play any of the other roles assigned to explicature content. Furthermore, as a reviewer pointed out, such a notion places a great deal of weight on the notion of intentions concerning direct communication (to stop everything in the speaker's mind relating to a communicative act getting in to the picture), but this notion of 'directness' is itself left unspecified. 
cognitive burden would be if our thoughts needed to incorporate relevant possibilities at the very outset, we would be unlikely to be able to move beyond entertaining a single thought. It would seem then that what the speaker has in mind need not in any way match the kind of 'slightly pragmatically enhanced' content envisaged by the canonical definition of explicature content.

\subsection{Explicatures as the First Proposition the Hearer Entertains via Relevance}

\section{Processing}

As is well-known, according to Relevance Theory, utterances come with a promise of optimal relevance and, in their search for the meaning of the utterance, hearers try out possible interpretations of the utterance until they reach one that crosses the threshold of relevance (i.e. which yields sufficient cognitive effects for a cheap enough processing cost). However, as with speakers, there is a question about whether or not explicature content (of the kind suggested by Pragmaticists) really is or need be entertained by hearers. Instead it seems at least possible that all hearers may entertain is some more removed pragmatic content (i.e. content that would intuitively be counted as an implicature not an explicature $)^{15}$. So, consider the cinema example from $\$ 2.2$ again. If I ask you to have dinner with me tonight and you respond with 'I'm going to the cinema' I think it's perfectly possible that I can grasp the proposition that you can't or won't have dinner with me, just given Grice's notion of 'what is said by the sentence' and an understanding of the context in which the sentence is produced. I don't have to entertain some intermediate proposition which slightly pragmatically enhances this literal meaning by specifying exactly when or where you are going to the cinema. Rather, I asked you a question, you chose not to answer it explicitly, and that, together with the literal meaning of the sentence you produced, is enough to tell me that your answer was 'no'. What carries the weight here are our social practices surrounding asking and answering questions, not some slightly-pragmatically

\footnotetext{
15 This point was recognised by Grice, see the quote in n.2.
} 
enhanced proposition. ${ }^{16}$ In this situation, either it must be allowed that the explicature of the utterance is 'B can't or won't have dinner with me' (since this is the first proposition I entertain), thus rejecting the canonical definition of explicature content, or we maintain the idea that explicature content is an intermediate proposition such as ' $\mathrm{B}$ is going to the cinema tonight' and reject functional definition (ii). Again, then, if we focus on the content in the mind of an interlocutor, we have no guarantee, I think, that the content we find there will be the kind of content the Pragmaticists are after.

\subsection{Explicatures as the Propositions which Warrant Recovery of Implicatures}

This connects closely to the point above: although it is clear that explicatures can play a crucial role for us as theorists in clarifying the inferential relation between the literal sentence meaning and the ultimate speaker meaning, it is not clear that this route need be realised in the mind of the interlocutor. Just as the Gricean model (where hearers arrive at implicatures only via inference from what the sentence says) is often held to be too cognitively onerous, so, the suggestion is, the Pragmaticist model (which requires hearers to always grasp an explicature and then use this to infer their way to implicatures) places too great a cognitive burden on hearers to be plausible as a theory of on-line utterance processing. ${ }^{17}$ Sometimes - with people we don't know or situations we are unfamiliar with - we need to do this kind of thing, to consider various stages of what the speaker might have meant, starting with slightly pragmatically enhanced contents and inferring our way to propositions which get closer to the ultimate point of what the speaker was saying, but most of the time, I want to suggest, we just grasp what the sentence says and that, together with sensitivity to a vast range of social and other information, is enough to get us all the way to full speaker meaning (implicatures and all). When the mother says to her child, who

\footnotetext{
${ }^{16}$ The suggestion then is that an account of communication should make greater use of scripts (see Schank and Abelson 1977) and schemas (see Brewer and Treyens 1981) than do current Pragmaticist models.

${ }^{17}$ For the processing-account challenge to Grice, see, e.g. Geurts \& Rubio-Fernández (forthcoming).
} 
has grazed his knee and is making a big fuss, 'You are not going to die', I suggest that hearers can know that she is telling the boy to calm down, to stop making such a fuss, etc., without their first having to entertain the proposition that 'the addressee is not going to die from that injury' or that 'the addressee is not going to die imminently'. When my friend tells me 'Robert is a computer' I can see (given the content of our conversation thus far) that she means Robert lacks feelings without first entertaining some ad hoc concept COMPUTER* of which Robert falls in the extension.

By thinking that we always need to cognitively reconstruct a full derivational route to speaker meaning, Pragmaticists seem to underestimate the power of the communicative frameworks and practices in which we are embedded. Instead, what I want to suggest is that our familiarity with speech acts like hyperbole, metaphor, sarcasm and irony, our knowledge of familiar conversational scripts and schemas, our grasp of prosody and body-language, our background knowledge of power-structures and social mores - all of these (and no doubt more beside) are what carry the cognitive weight when moving from standing meaning to communicated content. We need not and do not always have to engage in some carefully reconstructed deductive reasoning from standing meaning to speaker meaning via a slightly pragmatically expanded logical form. ${ }^{18}$

The considerations of this section reveal, I think, that if we focus on the minds of interlocutors and on the processes of on-line comprehension, we have no reason to think that the content we will find will be anything like the content predicted as explicature content by the canonical definition proposed by the Pragmaticists. Thus I think attempts to complete the canonical definition of explicatures via appeal to psychological content of this kind will not

\footnotetext{
${ }^{18}$ Echoing the debate about the Gricean model, we might allow that explicatures figure as part of a rational reconstruction of the communicative process without accepting that they are part of the on-line processing story.
} 
work. ${ }^{19}$ However, perhaps when we look to more public aspects of content, such as what proposition might ground or justify a further proposition, or to the legislative notion of what a speaker is held to have asserted, we stand a greater chance of finding something which matches the canonical notion of an explicature? It is this idea - that explicatures be defined through their role in the public sphere of communication - that underpins our final two functional definitions of explicature.

\section{Communication-based Definitions of Explicatures}

If the psychological contents which lie behind communicative acts are not guaranteed to match up with the canonical notion of an explicature, perhaps we might instead hope to shore up the incomplete canonical definition by appeal to the role explicatures play in a more third-personal understanding of communication. Perhaps if we look to public practices of assessing utterances as true or false, or to our shared intuitions about the content for which a speaker is directly responsible, given what linguistic item was produced in what context, we will find a content which matches the slightly pragmatically enhanced content envisaged by Pragmaticists? My conclusion however will be that, even if this is right, it doesn't actually help Pragmaticist positions.

\subsection{Explicatures as the Proposition by which a Speaker's Utterance is Judged Strictly}

\section{True or False}

Individuating explicature content as the propositional content by which a speaker's utterance is judged true or false seems problematic to me. The worry is that soliciting judgements of truth and falsity for utterance content influences the very phenomenon it is supposed to be

\footnotetext{
${ }^{19}$ As Geurts \& Rubio-Fernández (forthcoming) note 'Since communication is a form of social interaction, studying pragmatics on the premise that it is all 'in the mind' is like trying to understand traffic by studying car engines'.
} 
uncovering (there is, we might say, a kind of 'quantum effect'). To see this, let's return to Carston's party example from $\$ 1.3$ :

A: 'How was the party?'

B: 'There was not enough drink and everyone left'

Recall that the suggestion earlier was that the explicature of B's utterance was:

(B1) Explicature: there was not enough alcoholic drink to satisfy the people at the

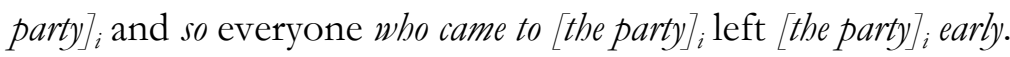

So the question we need to ask now to test this assessment is: in what circumstances is B's utterance true? For instance, we might ask if it is true if there was enough alcoholic drink at the party but it was held in a locked cupboard? And is it true only if everyone left early in the evening or early for a really wild party? Assuming that we think what B said was still true in the first circumstance but also true only if everyone left early in the evening then the explicature content should perhaps be:

- there was not enough easily available alcoholic drink to satisfy the people at [the party $]_{i}$ and so everyone who came to [the party] $]_{i}$ left [the party $]_{i}$ after early in the evening.

But now we can ask, is what B said true in a situation where there was plenty of crème de menthe available at the party, or where those hosting the party didn't leave? Perhaps in answer to those questions we need something like:

- there was not enough easily available and attractive alcoholic drink to satisfy the people at the

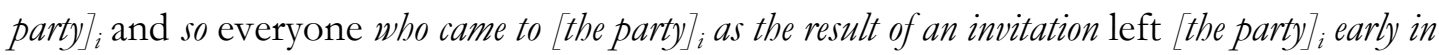
the evening.

In asking these questions I want to suggest that we prompt the audience to sharpen the original content of the utterance in various ways, but these moves reflect decisions about how to sharpen content not an uncovering of material which is already present. As already suggested above 
(\$3.1), this kind of practice doesn’t give us any reason to think that the content which gets added in response to the queries was in some way already present in the original assertion itself. ${ }^{20}$

\subsection{Explicatures as Asserted Content}

It seems unarguable that there is a distinction we intuitively recognise between content that a speaker explicitly communicates or directly asserts and content that she merely implies. In Grice's classic example, the referee who writes just 'Jones has nice handwriting' asserts only that Jones has nice handwriting but indirectly conveys so much more. In a discussion about headaches and the relative merits of over-the-counter remedies, the speaker who says 'Paracetemol is better' explicitly communicates that Paracetemol is better than aspirin for curing headaches, and thereby may imply that Jones, the headache sufferer on this occasion, should take paracetemol. This notion of explicit communication or asserted content is a public and a normative one - asserting comes with certain kinds of rights and responsibilities which mere implication lacks. For instance, one can cancel or withdraw from attributed implicatures in a way which one cannot from asserted content - in the latter context above, it seems that the speaker can't maintain (or at least it will not be admitted if she tries to maintain) that her utterance of 'Paracetemol is better' asserted merely that paracetemol is better than nothing, though she could maintain that she wasn't implying Jones should take some (for instance, because she knows Jones to be allergic to paracetemol but not aspirin).

So, could we just put the weight here on our intuitions about asserted versus implied content and take explicatures to be whatever content a community of speakers (or an expert panel) take to have been asserted? I think there are two problems with such a move. First, and most fundamentally, it makes explicatures explanatorily otiose. The aim of the Pragmaticist notion of an explicature was, I take it, to ground and explain our intuitions about asserted

\footnotetext{
${ }^{20}$ As Soames 2009: 15 notes, in a somewhat similar vein, '[o]f course...we could always have said more, but surely this is no reason to think that we have in effect already said more'.
} 
content. If we now seek to define explicatures simply through direct appeal to our intuitions about asserted content, no explanatory ground has been gained. Second, while it seems right that we as interlocutors have strong intuitions about what a speaker asserts versus merely implies, it is at least possible that these intuitions cross-cut the division between canonically defined explicatures and implicatures. For instance, sometimes we seem willing to allow that assertion lines up with some much more minimal content (closer to the compositional meaning of a sentence): when my son, under pressure, says 'I will get the washing in' and I return to find it still on the line, dripping in the rain, it seems he can escape at least some censure by pointing out that he only said he would get the washing in not when he'd get it (even though, in the original context of utterance, explicature content would surely extend to include a suitable timeframe).

Alternatively, in the other direction, it seems we sometimes hold a speaker responsible for a much richer content than merely the developed logical form of an explicature. For instance, UK defamation law can be applied to any false statement which causes a reasonable person to think less of the individual who is the subject of that statement. There is no distinction made between whether the libellous content was explicit or implicit, and indeed the history of successful libel cases reveals that judges (at least in the UK) are willing to take what we might intuitively think of as implicture content into account. ${ }^{21}$ While we might not choose to use the term 'asserted' for implicit libel, it seems that the normative force we above associated with assertion can attach to

\footnotetext{
${ }^{21}$ Take the infamous 1950's libel action by Liberace against the Daily Mirror, for an article which contained the following passage '[Liberace is] the summit of sex — the pinnacle of masculine, feminine, and neuter. Everything that he, she, and it can ever want... a deadly, winking, sniggering, snuggling, chromium-plated, scent-impregnated, luminous, quivering, giggling, fruit-flavoured, mincing, ice-covered heap of mother love'. Liberace sued the paper for libel, claiming it had portrayed him as a homosexual. Part of the paper's defence was that the article was not meant to imply that Liberace was gay, however the paper lost (presumably on the grounds that the article did carry the denied implication). Regardless of whether the passage implied this or not, what the case makes clear is that the fact that a defamatory content is not explicit is no defence in the eyes of the law.
} 
content very far removed from the kind of limited pragmatic enrichment that lies at the heart of explicature-based accounts.

So, even if we look directly to our intuitions about asserted content or concerning the content we hold speakers responsible for, we are not, I think, guaranteed to find anything which matches the canonical definition of the explicature. However, even were it to turn out that there is a useful notion of assertion which carves along the lines envisaged for explicatures, the point remains that such a notion cannot help the Pragmaticist cause. The Pragmaticist view we've been considering seeks to ground and explain our intuitions about what a speaker says/asserts in terms of the independently individuated notion of an explicature. If it turns out that the way we define explicatures is simply in terms of shared intuitions about asserted content, then no move has yet been made down the explanatory road.

\section{Conclusion}

I have tried to suggest in this paper that the key Pragmaticist notion of an explicature is illdefined. The canonical definition of an explicature, in terms of 'a development of logical form', is incomplete and is incapable, as it stands, of differentiating explicitly communicated versus merely implied content. Though there are formal tests which theorists have appealed to to try and bolster the official definition (e.g. in terms of the Scope Test, or the Locality Constraint) I argued that none of these formal approaches to defining explicatures worked. Instead, then, I suggested that a Pragmaticist might choose to try and append a functional definition to the canonical account, and we considered two kinds of functional analyses present in the literature: appeals to the psychological states of interlocutors and appeals to community-wide intuitions about asserted content itself. However I argued that neither of these functional moves can help the Pragmaticist: on the one hand, although there is of course content entertained by the speaker and hearer during on-line processing of communicative acts, we have no reason to think that this 
content will line up either with each other or with that held to be explicature content by Pragmaticists. On the other hand, though we do have intuitions about asserted content and a view about what a speaker can be held responsible for in saying what she did, it is also not clear that this content must always line up with what the canonical definition offers us as explicature content. Furthermore, if we appeal directly to our intuitions about asserted content in defining explicatures, it seems that no explanatory move has been made - if we end up thinking of explicatures as just 'whatever content a community judges a speaker to have asserted' then the notion of an explicature can do no work in grounding or explaining views about asserted content. The difficultly faced by explicatures, it seems to me, is that they are simultaneously defined in three very different ways: as a limited development of an otherwise incomplete logical form, as what the speaker or hearer has in mind when they are engaged in a communicative exchange, and as what answers to our public, legalistic notion of asserted content. However we have good reason to think that these three notions can and do pull apart from one another and thus that the notion of an explicature explodes.

The wider moral we should draw from this is, I think, that if the idea of a 'slightly pragmatically enhanced content' which lies behind the technical notion of an explicature has a useful home anywhere it is within the realm of socio-linguistics, as part of our attempt to understand the normative, legislative notion of what a speaker is actually committed to by her utterance. The Pragmaticist problem lies in thinking that any such legalistic notion must also play an interesting psychological role in on-line processing.

Reading Centre for Cognition Research and the Philosophy Department University of Reading

\section{Bibliography}


Bach, K. 1994: Conversational impliciture. Mind and Language 9, 124-62.

Bach, K. 2010: Impliciture versus explicature. In B. Soria \& E. Romero (eds), Explicit

Communication: Robyn Carston's Pragmatics. Palgrave Studies in Pragmatics, Language and Cognition.

London: Palgrave.

Borg, E. 2004: Minimal Semantics. Oxford: Oxford University Press.

Borg, E. 2012: Pursuing Meaning. Oxford: Oxford University Press.

Brewer, W. and Treyens, J.1981: Role of schemata in memory for places. Cognitive Psychology 13, 207-230.

Camp, E. 2012: Sarcasm, pretense, and the semantics/pragmatics distinction. Nous 46, 587-634.

Carston, R. 1988: Implicature, explicature, and truth-theoretic semantics. In R. Kempson (ed), Mental Representations. Cambridge: Cambridge University Press. 155-81.

Carston, R. 2002: Thoughts and Utterances. Oxford: Blackwell.

Carston, R. 2009: Relevance theory: contextualism or pragmaticism? UCL Working Papers in Linguistics 21.

Carston, R. 2009b: Pragmatics and the explicit/implicit distinction. International Review of Pragmatics 1, 35-62.

Carston, R. \& Hall, A. 2012: Implicature and explicature. In Schmid, H. J. (ed.), Cognitive Pragmatics. (Vol. 4). Mouton de Gruyter. 47-84.

Geurts, B. \& Rubio-Fernández, P. Forthcoming: Pragmatics and processing. In N.Hansen and E. Borg (eds), Investigating Meaning. Special volume, Ratio. 
Grice, P. 1989: Studies in the Way of Words. Cambridge, MA: Harvard University Press.

Hall, A. 2008: Free enrichment or hidden indexicals? Mind and Language 23, 426-456

Neale, S. 2007: On location. In O’Rourke, M. \& C. Washington (eds), Situating Semantics.

Cambridge, MA: MIT Press. 251-393.

Noveck, I. A. 2004: Pragmatic inferences related to logical terms. In I.A. Noveck \& D. Sperber (eds), Experimental Pragmatics. Basingstoke: Palgrave Macmillan. 301-321.

Perry, J. 1986. Thought without representation. Proceedings of the Aristotelian Society Supplementary Volume LX:263-283.

Recanati, F. 2002: Unarticulated constituents. Linguistics and Philosophy 25: 299-345.

Recanati, F. 2004: Literal Meaning. Cambridge: Cambridge University Press.

Schank, R. and Abelson, R. 1977: Scripts, Plans, Goals, and Understanding: an inquiry into buman knowledge structures. Hillsdale, NJ: Lawrence Erlbaum.

Soames, S. 2009: Philosophical Essays Vol. I. Princeton: Princeton University Press.

Sperber, D. and D. Wilson. 1986: Relevance: communication and cognition. Oxford: Blackwell.

Sperber, D. and D. Wilson (draft). Beyond speaker's meaning.

Stanley, J. 2002: Making it articulated. Mind and Language 17, 149-168.

Wilson, D. 2011: Parallels and differences in the treatment of metaphor in Relevance Theory and Cognitive Linguistics. Intercultural Pragmatics 8, 177-196. 